\title{
CONSIDERAÇÕES SOBRE O FEMININO E O REAL NA PSICANÁLISE
}

\author{
Cristina Moreira Marcos
}

\begin{abstract}
RESUMO. Em suas considerações sobre o feminino Lacan parte da tese de que é um ser que não se submete inteiramente ao Édipo. Privilegiando menos a castração do que a divisão introduzida na menina pelo primado do falo, ele funda suas interrogações a propósito do feminino na divisão da mulher entre os dois gozos. É na medida em que uma mulher não está completamente submetida à lei do significante que haveria a possibilidade de um gozo não-todo referido ao falo. Permanece um inominável, um real que desfruta um outro gozo, suplementar ao falo. A mulher, não inteiramente no simbólico, teria uma relação privilegiada com o real. Trata-se de se perguntar como podemos ler esta relação. Não pretendemos percorrer exaustivamente a teorização do real no ensino de Lacan, mas buscaremos afirmar alguns aspectos fundamentais deste conceito para melhor delimitar o que significa esta relação privilegiada das mulheres com o real.
\end{abstract}

Palavras-chave: Feminino; real; psicanálise.

\section{THE FEMININE AND THE REAL IN PSYCHOANALYSIS CONSIDERATIONS}

\begin{abstract}
The feminine is considered by Lacan as a being who does not submit entirely to Oedipus. By focusing less on castration than on the division introduced by the rule of the phallus, his questions about women are based on the women's division between the two jouissances. It is in that a woman is not completely subject to the law of the signifier that there would be a possibility of another jouissance. It remains a nameless, a real who enjoys another jouissance, additional to the phallus. The woman, not entirely in the symbolic, would have a privileged relationship with reality. We need to ask how this relationship should be read. We do not want to examine extensively Lacan's teaching on the real, but to present some aspects of this concept in order to clarify women's privileged relationship with this real.
\end{abstract}

Key words: Female; real; psychoanalysis.

\section{LO FEMENINO Y LO REAL EN EL PSICOANÁLISIS}

RESUMEN. Al centrarse en la división presentó a la niña por la primacía del falo, Lacan basa sus preguntas sobre el tema de la mujer en la división femenina entre las dos goces. Es en que una mujer no está totalmente sujeto a la ley del significante que habría una posibilidad de un goce otro. La mujer, no del todo en el simbólico, tendría una relación privilegiada con lo real. Hay que preguntar cómo podemos ver esta relación. No es ir al fondo a través de la teoría de lo real en Lacan, pero pensar en cómo algunos aspectos de este concepto puede arrojar luz sobre la relación privilegiada de la mujer con el real.

Palabras-clave: Feminidad; real; psicoanálisis.

Trata-se, neste artigo, de interrogar acerca da relação privilegiada das mulheres com o real, apontada por Lacan. Não se pretende percorrer exaustivamente a teorização e o lugar do real no ensino de Lacan, mas antes buscar afirmar alguns aspectos fundamentais deste conceito para melhor delimitar o que significa esta relação privilegiada das mulheres com o real e como ela pode ser lida. Para tanto, procedeu-se a uma revisão bibliográfica em Lacan, nos períodos de 1958 a 1960 e 1970 a 1975, para melhor elucidar as relações entre o real e o feminino. Encontramos, neste percurso, indícios do que seriam os antecedentes da noção de não-todo, que ganhará seus contornos definidos a partir de 1970.

Lacan aborda a questão da sexualidade feminina a partir da diferenciação entre o gozo fálico e o gozo suplementar. Em relação à identidade feminina, Lacan retoma o princípio freudiano do primado do falo como o representante da diferença entre os sexos no inconsciente através da postulação da inexistência de

\footnotetext{
Doutora em Psychopathologie fondamental et psychanalyse pelo Universite de Paris VII - Universite Denis Diderot, França.
} Professora Titular da Pontifícia Universidade Católica de Minas Gerais , Brasil. 
um significante d'A mulher. Quanto ao Édipo, ele afirma que as mulheres são não - todas inscritas na função fálica, assinalando um além do Édipo e um além da castração. Ao mesmo tempo em que estão submetidas ao Édipo e à castração, elas deles escapam. Finalmente, quanto à sexualidade, ele enfatiza menos uma mudança de sexo (do masculino para o feminino) e de objeto (do clitóris para a vagina) do que um suplemento que viria se acrescentar ao gozo fálico.

O feminino é analisado por Lacan a partir da tese de um ser que não se submete inteiramente ao Édipo e à lei da castração. Privilegiando menos a identidade do que o gozo feminino, menos a castração e a inveja do pênis do que a divisão introduzida na menina pelo primado do falo, ele funda suas interrogações a propósito do feminino na divisão da mulher entre os dois gozos.

$\mathrm{Na}$ teoria lacaniana, o falo e a castração não se colocam mais como obstáculo à feminilidade, mas como suas condições. Para abrir as portas ao tornar-se mulher, Freud se apoia na divergência das consequências do complexo de castração no menino e na menina, enquanto para Lacan a menina não disporia somente da referência à castração para tornarse mulher.

É na medida em que uma mulher não está completamente submetida à lei da palavra e ao gozo que daí resulta que haveria a possibilidade de um outro gozo não-todo referido ao falo. Resta um inominável, um real que goza de um gozo diferente, suplementar ao falo. A divisão não é feita entre a vagina e o clitóris ou entre atividade e a passividade, mas segundo a divisão que separa a linguagem e o corpo, o real e o simbólico. A mulher, não inteiramente no simbólico, teria uma relação privilegiada com o real.

\section{O REAL}

A visão psicanalítica acerca da diferença sexual mostra que o real da psicanálise não é o real da ciência. A ciência descobre um saber no real do qual ela deduz leis que possuem um valor universal. Ela pode predizer o que se passa no real através de experiências empíricas. No que concerne à reprodução da espécie, a ciência pode descrever as leis às quais são submetidas a concepção e evolução embrionárias.

Em psicanálise, não podemos traçar leis universais, deduzidas da experiência, para predizer o que tal sujeito faria colocado em tal situação. É verdade que existe um saber sobre as estruturas clínicas, sobre a sexualidade infantil, sobre o funcionamento do aparelho psíquico, assim como há um saber do caso clínico, mas que não precede a experiência da análise. Não há meios de conceber regras ou leis que regeriam as relações entre um homem e uma mulher como a ciência faz em relação ao comportamento de um espermatozóide e de um óvulo. O real, para a psicanálise, é esta ausência de lei para predizer as relações sexuais, ou melhor, é a ausência de uma escrita da relação sexual e as consequências, para cada um, deste defeito. Daí o aforisma lacaniano : « Não há relação sexual ».

Na psicanálise, o real é este buraco que, para o ser falante, vem no lugar das leis que determinam a vida sexual animal. Ele é esta impossibilidade de escrever a relação sexual. Lacan lê, nos textos freudianos sobre a sexualidade, uma falta original no imaginário dos seres humanos. Contrariamente à vida animal, plena e sem falhas, a vida humana é regida por um imaginário marcado pelo buraco, por um hiato real.

$\mathrm{O}$ real não é então o que nomeamos como realidade, mesmo que seja verdadeiro dizer que é por meio da realidade que o abordamos. Ao contrário, ele é o que escapa à realidade, o que não se inscreve no simbólico; ele envia ao traumático, ao inassimilável, ao impossível. Lacan fala em «pedaço » ou em « resto de realidade ». O real tem relação com a realidade, mas para designar um ponto que escapa ou resiste à simbolização desta. Assim ele é definido como o que «não se liga a nada», que está «excluído do sentido », «impensavél», «no limite de nossa experiência ».

Desde 1953, na conferência pronunciada no momento da fundação da Société Française de Psychanalyse sob o título «Le symbolique, l'imaginaire et le réel» (Lacan, 1953/1987), Lacan estabelece uma tripartição estrutural como elementar, sem a qual nada pode ser distinguido na experiência analítica. O real já é apresentado aí como o que constitui os limites da nossa experiência, o que nos escapa na cura.

O fora do simbólico, no seminário sobre as psicoses, a qualidade de um objeto ou de uma operação no seminário sobre o objeto, o irrepresentável de das Ding no seminário sobre a ética, o inassimilável do trauma ou a inalcançável satisfação da pulsão no seminário sobre os quatro conceitos fundamentais, o real vai ganhando importância ao longo do ensino de Lacan para tornar-se o centro do que se passa na experiência analítica.

Em «O seminário livro 1: Os escritos técnicos de Freud» (Lacan, 1953-1954/1986), o real já é introduzido a partir da noção de forclusão, mesmo se este termo ainda não figura como tradução do termo 
alemão Verwerfung. Lacan toma do texto freudiano o termo Verwerfung e o traduz primeiramente por recusa, apoiando-se para isto na leitura de «Die Verneinung » de Freud feita por Jean Hyppolite. Dois fatos clínicos lhe permitem afirmar que o que é rejeitado no simbólico retorna no real: a alucinação do dedo no Homem dos Lobos e o esquecimento de Freud de Signor em Signorelli.

Lacan descreve a forclusão como o mecanismo fundamental que está na base da psicose. Nova tradução proposta para o termo freudiano Verwerfung, a forclusão designa a recusa de um significante primordial. «Trata-se de um processo primordial de exclusão de um interior primitivo que não é o interior do corpo, mas aquele de um primeiro corpo de significante »(Lacan, 1955/1956, p. 171) [tradução nossa]. Antes de estar reservado ao vocabulário jurídico, «forcluir » significava excluir, privar, banir. Este verbo contém a ideia de fechar do lado de fora ou de fechar no exterior. Em seu sentido jurídio, a forclusão significa a prescrição de um crime, o limite além do qual o crime cometido não será mais condenado.

O real é justamente o fora do simbólico, o que dele está excluído. O que está excluído não está portanto desaparecido mas, ao contrário, retorna alhures. O que é forcluído do simbólico reaparece no real sob a forma alucinatória. A postulação do real é necessária para explicar as manifestações patológicas da psicose como as alucinações que, por sua vez, pemitem melhor delimitar o real como sendo o forado-simbólico.

Em «Le séminaire livre IV La relation d'objet » (Lacan, 1956-1957/1994), Lacan situa as operações castração, frustração, privação a partir do real, do simbólico e do imaginário. Estes termos designam a qualidade de um objeto e de uma operação pela qual se realiza uma falta do objeto. Assim fazendo, o real e o objeto se distinguem, o real designando não somente o objeto mas também a operação pela qual a falta do objeto se introduz.

Em «Le séminaire livre VII: L'éthique de la psychanalyse » (Lacan, 1959-1960/1986), o autor tenta delimitar o lugar de das Ding, termo que encontramos no «Projeto» de Freud. A primeira apreensão da realidade é a realidade do Outro, o primeiro objeto de satisfação que se torna objeto hostil. Das Ding é a parte inassimilável do primeiro exterior do sujeito. Não representável, das Ding escapa à memorização. É um resto que, não obstante, faz parte do investimento da realidade. A coisa é o fora-do-significado, o irrepresentável.
A partir de "Le séminaire livre XI: Les quatre concepts fondamentaux de la psychanalyse » (Lacan, 1964/1973), Lacan começa a teorizar o real como impossível. O comentário do sonho que abre a Traumdeutung nos fornece esta formulação. Um pai cujo filho morreu dorme enquanto um velho vela a criança morta. Ele sonha que a criança está perto da sua cama, lhe toma o braço e murmura em um tom pleno de reprovação: "Pai, não vês que estou queimando ? » (Freud, 1990/1987, p. 433). Ora, este pai acorda, corre ao cômodo ao lado e vê o velho dormindo e um braço do filho morto queimado por um cierge caído sobre ele.

Onde poderíamos supor uma equivalência entre o conteúdo manifesto do sonho e a realidade, Lacan vê uma distância onde se situa o real. O real é o encontro faltoso entre o sonho e a realidade. A distinção aristotélica entre a tychê e o autômaton esclarece a natureza deste encontro. $\mathrm{O}$ autômaton corresponde a um desdobramento automático da cadeia significante no inconsciente. Ele envia «ao retorno, à volta, à instância dos signos nos quais nos vemos comandados pelo princípio do prazer» (Lacan, 1964/1973, p. 54) [tradução nossa]. Por outro lado, a tychê é o encontro com o real, além do autômaton. $\mathrm{O}$ real aqui é o que faz uma ruptura no funcionamento tranquilo do autômanton, no encadeamento automático submetido à lei dos significantes do sujeito do inconsciente.

Lacan afirma que a função de tyché, do real como encontro, é apresentada na origem da experiência analítica sob a forma do traumatismo. Ainda nesse seminário, ele é levado, a partir da pulsão, a definir o real como impossível. A satisfação que a pulsão almeja é tão somente parcial, ela inscreve um impossível a alcançar. Ela faz o contorno do objeto.

A partir de «Le séminaire le livre XIII: L'objet de la psychanalyse » (Lacan, 1965-1966), Lacan localiza cada vez mais o real a partir de uma relação com a lógica. É através da lógica que ele pode afirmar que a relação sexual não se escreve. $O$ significante que permitiria escrever a relação do homem à mulher falta na cadeia - portanto não há relação sexual que possa se escrever.

Na última parte de seu ensino, o real é abordado a partir de sua relação com o imaginário e com o simbólico. $\mathrm{O}$ ponto de partida para este desenvolvimento situa-se em «Le séminaire livre XIX: Ou pire» (Lacan, 1971-1972). O nó borromeano, três anéis ligados de tal modo que se um se solta os outros dois encontram-se livres, permite a Lacan um avanço no seu modo de pensar a relação entre o real, o simbólico e o imaginário. 


\section{O FEMININO, O NÃO-TODO E SEUS ANTECEDENTES}

Como pensar a relação particular que as mulheres teriam com o real ? Em sua leitura do sonho da injeção de Irma, Lacan (1954-1955/1995) vê uma abordagem do real por Freud. Neste sonho, «um documento onde podemos ler literalmente a relação freudiana com a feminilidade» (Assoun, 1995, p. 61) [tradução nossa]. Lacan vê uma janela que se abre sobre a carne viva sem ornamento e sem erotização. Há aí a revelação de alguma coisa de inominável, afirma Lacan, e o início da elaboração de uma resposta a este real.

Segundo Serge André (1987/1986) Freud encontra o inominável no sonho sob a forma de três figuras: a carne viva, onde o órgão sexual feminino aparece dessexualizado; a morte, na medida em que o feminino se aproxima do mutismo; o umbigo do sonho, a lacuna no psiquismo. O sonho da injeção de Irma, que tem um valor inaugural da relação da psicanálise com o feminino, constitui-se em torno da questão sobre o que é uma mulher. Ponto de partida da via de acesso ao feminino, este sonho não é outra coisa senão o encontro com o inominável, o encontro com o real.

Outra mulher, Emmy (Breuer \& Freud, 1893/1987), permite perseguir esta relação da mulher com este ponto que escapa à simbolização. Esta mulher apresenta-se a Freud em voz baixa, como se tivesse dificuldade em falar. Sua palavra, de tempos em tempos, sofria interrupções espasmódicas a ponto de gaguejar. Além disto, ela produzia um barulho bizarro com a boca. Serge André (1986) lê aí um sintoma particular: um buraco na palavra. Em seu discurso, parece que uma interrupção torna literalmente presente a lacuna na qual Freud situa o trauma. Estes espasmos na palavra de Emmy parecem reenviar ao buraco, à lacuna pela qual o real se manifesta. Não se trata simplesmente de um silêncio, mas da presença de alguma coisa de inominável que impõe a ruptura da cadeia discursiva.

Suas lembranças giram em torno da passagem do estado animado ao inanimado, ou o contrário. É o velamento do real pelo significante que é interrogado. Esta coisa inominável que irrompe deixa Emmy muda. Ela a disfarça pelos significantes do rato, do cadáver, do animal morto. Emmy tem medo de que ela mesma se transforme em coisa morta, corpo inanimado. $\mathrm{O}$ valor traumático destes eventos parece ligado ao fato de que eles tornam presente para o sujeito um real sem ornamento, não recoberto pelo significante, sobre o qual o sujeito nada pode dizer.

Se o furo na palavra, no caso Emmy, envia-nos à coisa morta, ao real orgânico, ele nos faz ver também a lacuna na memória. Freud reconhece que, apesar de suas injunções, ele não consegue fazer desaparecer o sofrimento de Emmy. Pode se resumir seu sucesso na submissão da paciente à autoridade de seu médico, seja sob a forma de um dom de seu sintoma - «Eu estou melhor mas somente porque você me disse isto.», seja sob a forma de uma promessa : «Eu ficarei melhor porque você me ordenou isto.» (Breuer \& Freud, 1893/1987, p.107). Não obstante, o elemento sexual (tão buscado e ausente das reminiscências da paciente) e a cura não se realizam. $O$ furo na palavra de Emmy parece exibir literalmente que existe um silêncio no interior da palavra. Há aí algo de inabordável, que escapa à apreensão do simbólico. $\mathrm{O}$ encontro inaugural de Freud com o feminino não é outra coisa senão o encontro com este real inominável.

Havíamos dito anteriormente que um modo de ler a relação privilegiada das mulheres com o real seria a falta de representante do sexo feminino no inconsciente. O sonho da injeção de Irma e sua leitura feita por Lacan nos permitem pensar que o encontro da psicanálise com o feminino foi um encontro com o inominável, com o que escapa, o que resiste à apreensão pelo simbólico. O sexo feminino teria então uma relação com o que está fora do simbólico, com a falta, com o furo, com o hiato no interior do simbólico.

Lacan permanecerá fiel a esta definição do real como o impossível de simbolizar. A tripartição RSI se constitui para Lacan a partir da interrogação central da psicanálise, a saber, a questão da diferença sexual. No seminário sobre os quatro conceitos fundamentais, a realidade do inconsciente é definida como sexual. Lacan faz uma distinção entre a sexualidade biológica e a sexualidade social. Uma é orientada em direção à reprodução, enquanto a outra é orientada em direção à busca de alianças ou de filiações, quer dizer, trata-se de uma combinatória de significantes. A pulsão tem relação com o significante, com a cadeia significante, e não com a diferença sexual biológica. $\mathrm{O}$ significante sexual não é outro senão o falo, definido por Lacan como o significante da diferença.

É através da teorização do não-todo que Lacan tentará formalizar a particularidade da relação ao falo e ao real na mulher. A noção do não-todo é também um modo de pensar esta relação como uma interrupção do real na mulher que não é inteiramente tributária da castração. Antes mesmo dos anos setenta, momento de seu ensino em que a noção do não-todo ganha forma, Lacan já havia assinalado a dissimetria entre os dois sexos no que concerne ao falo e já podemos ler o que seriam os antecedentes de uma teoria da relação singular da mulher com o real. 
Em «O seminário livro 3: As psicoses» (Lacan, 1955-1956/1981) Lacan sublinha a importância de acentuar as dissimetrias, já observadas por Freud, no complexo de Édipo da menina e do menino. Estas distinções atestam aquelas do imaginário e do simbólico. A sexualidade do sujeito não se realiza apenas no plano simbólico, é esta a lição do complexo de Édipo.

Ele acrescenta que, para a mulher, o complexo não se realiza pela identificação à mãe, mas sim, pela identificação ao pai, o que é descrito como um desvio suplementar. Esta definição da identificação da menina ao pai permite dizer que a relação com o falo, na menina, não tem nada de natural. Aqui, uma passagem do texto lacaniano merece especialmente nossa atenção : o que poderia ser entendido como um dano no que concerne ao acesso à identidade de seu próprio sexo transforma-se numa vantagem na histérica. A histeria pode ser entendida como uma resposta à questão do feminino. Lacan (19551956/1981) afirma que:

Para a mulher, a realização do seu sexo não se faz no complexo de Édipo de modo simétrico ao do homem, não por uma identificação à mãe, mas ao contrário por uma identificação ao objeto paterno, o que lhe assinala um desvio suplementar. (...) Mas esta desvantagem na qual se encontra a mulher quanto ao acesso à identidade de seu próprio sexo, quanto à sexualização enquanto tal, transforma-se na histeria em uma vantagem, graças à sua identificação imaginária ao pai, que lhe é perfeitamente acessível, em razão especialmente de seu lugar na composição do Édipo. (p. 193)

Em algumas aulas deste seminário, Lacan (19551956/1981) enfatiza como essencial a dissimetria entre os dois sexos no Édipo e situa sua razão no simbólico, colocando-a na dependência do significante.

Não há propriamente falando, diríamos, simbolização do sexo da mulher enquanto tal. Em todo caso, a simbolização não é a mesma, não tem a mesma fonte, não tem o mesmo modo de acesso que a simbolizaçõ do sexo do homem. E isto porque o imaginário fornece apenas uma ausência, ali onde alhures há um símbolo muito prevalente. (p. 198)

O Édipo significa que as vias de acesso à realização subjetiva passam pelo significante. Lacan (1955-1956/1981 ) afirma que tudo está colocado para que a menina tenha uma experiência da posição feminina que seja direta e simétrica à do menino. Na realidade, isto se passa de outro modo - o sexo feminino é forçado a tomar a imagem do outro sexo como base de sua identificação. Este desvio só pode ser explicado através do simbólico.

Ali onde não há material simbólico, há
obstáculo, falha, na realização da
identificação essencial à realização da
sexualidade do sujeito. Esta falha vem do
fato que, em um ponto, falta material ao
simbólico - pois lhe é preciso algum. O sexo
feminino tem uma característica de ausência,
de vazio, de buraco, que faz com que
aconteça ser menos desejável do que o sexo
masculino no que ele tem de provocante, e
com que uma dissimetria essencial apareça.
Se tudo devesse ser entendido na ordem de
uma dialética das pulsões, nao se veria
porque um tal desvio, uma tal anomalia seria
necessária. (p. 199)

A função do homem e da mulher é simbolizada e arrancada do domínio imaginário - esta é a palavra escolhida por Lacan para falar da relação do ser falante com suas posições sexuais - arrancada - para se situar no domínio do simbólico, onde todas as posições sexuais se realizam.

Neste retorno à dissimetria essencial do Édipo, extraída dos textos freudianos sobre a diferença sexual, vimos a particularidade da relação da menina com o falo. Neste momento do ensino de Lacan, tratase ainda de explicar a singularidade do simbólico.

Nas teorizações sobre as três formas da falta - a frustração, a castração e a privação - em «Le séminaire livre IV: La relation d`objet » (Lacan, 19561957/1994) temos já um elemento novo para compreender a relação da mulher com a castração e com o falo, embora, neste seminário, seja sempre o simbólico o que conduz o modo de pensar tais relações. A tese freudiana segundo a qual o pênis do qual se trata no fetichismo não é qualquer um é retomada e, a partir daí Lacan, conclui que não se trata do pênis real. Trata-se de um falo simbólico, «enquanto é da sua natureza apresentar-se na troca como ausência, ausência funcionando enquanto tal» (Lacan, 1956-1957/1994, p.152) [tradução nossa]. Ele acrescenta que o que se pode transmitir na troca simbólica é sempre alguma coisa que é tanto presente como ausente. É algo que circula deixando a marca de sua ausência. O falo é um objeto simbólico. É na medida em que ele é presente ou ausente que se instaura a diferença sexual. Esta definição do falo com simbólico será essencial na abordagem da relação da 
mulher com a falta e com a castração. Lacan (19561957/1994) afirma:

Esse falo, a mulher não o tem, simbolicamente. Mas não ter $o$ falo simbolicamente é participar dele a título de ausência, é então tê-lo de algum modo. O falo está sempre mais além de toda relação entre o homem e a mulher. (p. 153)

No plano imaginário, a mulher pode sentir o falo que ela tem como pequeno ou insuficiente; entretanto, o falo imaginário não é o único a entrar no jogo das posições sexuais. Para além dela, há este falo que ela não tem, mas que existe enquanto ausência, o falo simbólico. É na medida em que ela não tem o falo, quer dizer, que ela não o tem simbolicamente, que ela encontra uma posição sexual na diferença entre os sexos. Lacan (1956-1957/1994) acrescenta um novo elemento: ele precisa que o buraco, a ausência, da qual se trata na mulher, é da ordem do real, de uma falta real, e deve ser considerado como privação, a falta é no real:

Quando eu digo, tratando-se da privação, a falta é no real, isto quer dizer que ela não é no sujeito. Para que o sujeito aceda à privação, é preciso que ele conceba o real como podendo ser outro que ele não é, quer dizer que ele o simbolize. (p. 55) [tradução nossa]

Lacan (1956-1957/1994) afirma que se deve considerar a falta do objeto em seus diferentes níveis o nível da cadeia simbólica, o nível da frustração e também o nível do real - no real. A privação é no real, fora do sujeito. Para que ele o apreenda, primeiro é preciso que ele simbolize o real. Temos aqui um modo de relação da mulher com o real, na medida em que se trata, nela, de uma falta real. Para ter acesso a este real é preciso que ela o simbolize. Os anos seguintes serão essenciais para a consolidação de uma teoria lacaniana sobre a posição sexual feminina, na qual o real gradativamente ganhará importância.

\section{CONSIDERAÇÕES FINAIS}

Nos anos situados entre 1958 e 1960, podemos ler uma teoria da relação da mulher ao falo que começa a ser formulada ; mas, neste esforço mesmo de dar conta dessa relação ao falo, os indícios de um outro pensamento podem ser destacados. Subrepticiamente começa a surgir a ideia segundo a qual a relação ao falo não saberia responder inteiramente à questão do feminino.

Lacan (1958-1960/1966), em «Remarques sur le rapport de Daniel Lagache», não diverge de Freud quando propõe como fórmula do desejo feminino o A barrado (phi). Trata-se de uma falta que produz o desejo pelo falo, a inveja do pênis - a nostalgia da falta a ter. É a primeira fórmula do desejo feminino proposta por Lacan, e ela não é outra coisa além do fim de análise freudiano. $\mathrm{O}$ final de análise de uma mulher é, para Freud, o Penisneid. Ainda é preciso lembrar que o Penisneid seria o que encaminha as mulheres em direção ao desejo, ao fim do Édipo. Nós temos então a fórmula lacaniana do Penisneid - o A barrado (phi). É uma solução para o Édipo, que não sai do Édipo: à privação responde-se pelo ter. Em «La signification du phallus», Lacan (1958/1966) introduz uma relação mais complexa com o falo que se traduz pela fórmula - «ter o falo». «Por mais paradoxal que possa parecer esta formulação, dizemos que é para ser o falo, quer dizer, o significante do desejo do Outro, que a mulher vai rejeitar uma parte essencial da feminilidade, nomeadamente todos os seus atributos na mascarada» (Lacan, 1958/1966, p. 694) [tradução nossa].

Não se trata de ter o falo, mas de sê-lo, de parecer-se com ele - um parecer se substitui ao ter. A mascarada vem se acrescentar à fórmula lacaniana do desejo feminino como um modo particular de a mulher se relacionar ao falo; entretanto, não podemos esquecer que isto se faz na rejeição dos atributos da feminilidade. Lacan (1958/1966) continua:

É pelo que ela não é que ela quer ser desejada ao mesmo tempo que amada. Mas ela encontra o significante do seu desejo no corpo daquele a quem ela endereça sua demanda de amor. Sem dúvida não podemos esquecer que dessa função significante, o órgão que é revestido desta função, adquire valor de fetiche. Mas o resultado para a mulher continua sendo que convergem sobre o mesmo objeto uma experiência de amor que, como tal, a priva idealmente do que ele dá, e um desejo que encontra aí seu significante. (p. 694) [tradução nossa]

Há aqui uma aparente convergência entre o objeto do amor e o objeto do desejo, o que, segundo Lacan, explicaria a tolerância das mulheres à frigidez. De fato, ela encontra o significante do seu desejo no órgão de seu parceiro que, revestido da função significante, toma valor de fetiche, podendo escolher o mesmo homem como o outro do amor. 
Por outro lado, em Propos directifs pour un Congrès sur la sexualité féminine», é evidente que esta convergência aparente recobre uma outra, a duplicidade do sujeito. «Em um nível mais terra-aterra, damos conta : a) de que a duplicidade do sujeito é encoberta na mulher tanto mais que a servidão do cônjuge o torna especialmente apto a representar a vítima da castração (...)» (Lacan, 1960/1966, p. 734) [tradução nossa].

Permanece a questão de se saber em que esta duplicidade coloca-se em relação com uma outra, a do gozo, colocada em evidência a partir da noção do nãotodo. A hipótese segundo a qual haveria algo de suplementar ao falo na mulher é um outro modo de leitura da relação privilegiada das mulheres com o real. É este desdobramento do sujeito feminino que Lacan vai formalizar melhor em «Le séminaire livre XX: Encore» (Lacan, 1972-1973/1975).

Como conceber que o Outro possa ser em algum lugar aquilo em relação a quê uma metade - porque também é grosseiramente a proporção biológica - uma metade dos seres falantes se refere? É entretanto o que está escrito lá no quadro com aquela flecha partido do A (barrado). Esse A (barrado) não se pode dizer. Nada se pode dizer da mulher. A mulher tem relação com $\mathrm{S}$ (de A barrado), e já é nisso que ela se duplica, que ela não é toda, pois, por outro lado, ela pode ter relação com o falo. (p. 75) [tradução nossa]

A feminilidade deve ser compreendida neste desdobramento entre S (de A barrado) e o falo. À época deste seminário, o falo dizia respeito à castração simbólica. Ele seria a função fálica ou a função castração, ele, o fato de que para satisfazer as necessidades vitais, deve-se passar pelos desfiladeiros do significante. É assim que podemos compreender a castração nesse momento do ensino de Lacan (19721973/1975). S (de A barrado), «esse lugar onde vem se inscrever tudo o que pode se articular do significante», Lacan o define como sendo, «em seu fundamento, radicalmente Outro. É por isto que esse signficante, com este parêntese aberto, marca o Outro como barrado - S (de A barrado)». (p. 75) [tradução nossa]

Não se pode esquecer que Freud define o homem e a mulher por um «ter ou não ter o falo ». As três saídas para a inveja do pênis - a renúnica, a masculinidade e a feminilidade - são soluções que passam pelo «ter», mas Lacan desloca a questão em direção a um «ser o falo». Certamente, o «não ter» condiciona, para a mulher, sua posição de objeto fálico.É a ausência do falo que a faz falo. Revela-se que a referência ao «ter ou não o falo» para definir a sexuação foi constante no ensino de Lacan. Em 1972 ele afirma no

«L'étourdit»: «Não há nada de excessivo, a partir do que nos dá a experiência, em colocar na conta do ser ou ter o falo (cf. minha Bedeutung dos Ecrits) a função que faz suplência à relação sexual». (Lacan, 1972, p. 14) [tradução nossa]

Ainda neste texto, Lacan (1972) refuta o Édipo como mito para reduzí-lo à lógica da castração; mas ele não faz objeção ao falocentrismo freudiano: o falo é o significante mestre da relação sexual, ordenador da diferença sexual e das relações entre os homens e as mulheres. Não obstante, a lógica da castração não regula todos os gozos.

Em 1958, trata-se de pensar o feminino a partir de uma locução complexa que não vemos em Freud, a saber, de pensá-lo em termos de «ser o falo». Temos aqui um além de Freud, na medida em que saimos do ter ou não ter o falo freudiano, que, aliás, é o obstáculo do final de análise das mulheres em Análise terminável e interminável (Freud, 1937/1987) em 1937. É somente a partir da escrita das fórmulas da sexuação, escritas a partir da função fálica, é preciso dizê-lo, que Lacan vai, em 1972, torcer o «ter ou não ter o fal » e o «ser ou não ser o falo» de 1958. As fórmulas lhe permitem alojar, se assim podemos dizer, o falo do lado masculino e escrever um lado feminino que, embora passe pelo falo, assinala um além do Édipo, um além do falo, escrevendo assim uma outra lógica, a lógica do nãotodo.

Colette Soler (2003) afirma que há no «L'étourdit» uma mudança. Se, em 1958 Lacan deriva a fórmula da posição sexual feminina, ser o falo, da falta fálica, esta tese se modifica com o L'étourdit e com «Mais ainda» (Lacan, 1972-1973/1975). Em 1958, Lacan afirma que é pelo que ela não é que ela pretende ser amada ao mesmo tempo que desejada e que assim sacrifica, na mascarada, uma parte essencial da sua feminilidade. Para atuar como causa do desejo, a mulher tem como única saída a mascarada feminina. Para ser o objeto do desejo do Outro ela se veste do falo, ela se torna o falo para ser desejada e nesta alienação no falo ela deixa de lado a essência do feminino ; mas no «L'étourdit» e no «Mais ainda», temos uma outra tese. Lacan aborda a posição feminina a partir do gozo. O gozo Outro, suplementar, não é um gozo identificatório, é um gozo que ultrapassa o sujeito e não o identifica. É porque o gozo a ultrapassa e não identifica que ela se esforça para se 
identificar através do amor de um homem e exige ser a única.

Se tudo o que é da ordem da sexualidade para o sujeito humano deve passar pelo parecer, isto se conjugará de modo diferente do lado masculino e do lado feminino. A posição masculina consistiria na proteção, ao passo que a feminina, na mascarada (Lacan, 1958/1966). Sabemos que este termo é tomado de empréstimo por Lacan a Joan Rivière no texto «A feminilidade enquanto mascarada» (1929/2005). Lacan diversas vezes saúda este trabalho, no qual temos como argumento principal a tese de que o feminino não é nada além de uma máscara. Parece-nos que a noção de semblante na psicanálise foi inventada a partir de uma aproximação da sexualidade feminina e que esta categoria, o semblante, permite articular de modo mais íntimo e menos hierárquico o real e o simbólico. Lacan parece ter levado às últimas consequências a questão da mascarada feminina ou do feminino enquanto mascarada; e podemos dizer que foi a partir do feminino que ele pôde pensar o semblante em sua articulação com o real e com o simbólico. Embora as mulheres façam uso do semblante se vestindo de falo, seja para tamponar a falta, seja para causar o desejo, elas parecem saber, mais do que os homens, que o falo não passa de um semblante (Miller, 2001). O semblante é a característica mesma do discurso, mas é o real do gozo ao qual as mulheres têm acesso que permite lembrar sua dupla face voltada para o real e para o simbólico.

\section{REFERÊNCIAS}

André, S. (1987). O que quer uma mulher. (D.D. Estrada, Trad.). Rio de Janeiro: Zahar. (Original publicado em 1986).

Assoun, P. L. (1995). Freud et la femme. Paris: Payot.

Breuer, J., \& Freud, S. (1987). Estudos sobre histeria. (J. Salomão, Trad.). In Edição Standard Brasileira das Obras Psicológicas Completas (Vol. II, pp.57-79). Rio de Janeiro: Imago. (Original publicado em 1893).

Freud, S. (1987). A interpretação dos sonhos. (J. Salomão, Trad.). In Edição Standard Brasileira das Obras Psicológicas Completas (Vol. IV). Rio de Janeiro: Imago. (Original publicado em 1900).

Freud, S. (1987). Análise terminável e interminável. (J. Salomão, Trad.). In Edição Standard Brasileira das Obras Psicológicas Completas (Vol. XXIII). Rio de Janeiro: Imago. (Original publicado em 1937).

Freud, S. (1987). História de uma neurose infantil. (J. Salomão, Trad.). In Edição Standard Brasileira das Obras Psicológicas Completas
(Vol. XVII). Rio de Janeiro: Imago. (Original publicado em 1918).

Lacan, J. ( 1966). «La signification du phallus». In J. Lacan. Ecrits. Paris: Seuil. (Original publicado em 1958).

Lacan, J. ( 1966). «Propos directives pour un congrès sur la sexualité féminine». In J. Lacan. Ecrits. Paris: Seuil. (Original publicado em 1960).

Lacan, J. ( 1966). «Remarques sur le rapport de Daniel Lagache». In J. Lacan. Ecrits. Paris: Seuil. (Original publicado em 1958-1960).

Lacan, J. ( 1975). Le séminaire le livre XX - Encore. Paris: Seuil. (Original publicado em 1972-1973).

Lacan, J. (1965-1966). L'objet de la psychanalyse Livre XIII. Inédito.

Lacan, J. (1971-1972). Ou pire Livre XIX. Inédito.

Lacan, J. (1973). Le séminaire de livre XI Les quatre concepts fondamentaux dans la psychanalyse. Paris: Seuil. (Original publicado em 1964).

Lacan, J. (1986). Le séminaire livre VII: L'éthique de la psychanalyse. Paris : Seuil. (original publicado em 1959/1960).

Lacan, J. (1986). O seminário - livro I - Os escritos técnicos de Freud. (M.C. Laznik, Trad.). Rio de Janeiro: Zahar. (Original publicado em 1953-1954).

Lacan, J. (1987). Le symbolique, l'imaginaire et le réel. Conférence à la SFP. Fragments, 3. Bulletin intérieur de l'EFP. (Original publicado em 1953).

Lacan, J. (1995). O seminário - livro II - O eu na teoria de Freud e na técnica da psicanálise. (M.C. Laznik, Trad.). Rio de Janeiro: Zahar. (Original publicado em 1954-1955).

Lacan, J.( 1981). Le séminaire livre III Les psychoses. Paris: Seuil. (Original publicado em 1955-1956).

Lacan, J.( 1994). Le séminaire le livre IV - La relation d'objet. Paris: Seuil. (Original publicado em 1956-1957).

Lacan, J.(1972) Etourdit. Scilicet, 4.

Miller, J. A. (2001). Da la naturaleza de los semblantes. Buenos Aires: Paidós.

Rivière, J. (2005). A feminilidade como máscara. (Trad. A.C. Carvalho, Trad.) Psyché, 9(16), 13-24. (Original publicado em 1929).

Soler, C. (2003). Ce que Lacan disait des femmes. Paris: Editions du Champ lacanien.
Endereço para correspondência:
Cristina Moreira Marcos. Rua Paschoal Carlos Magno, 68, Bairro: Ouro Preto, CEP 31310510, Belo Horizonte-MG, Brasil.E-mail: cristinammarcos@gmail.com. 